\title{
Critical Energy for Direct Initiation of Spherical Detonations in $\mathrm{H}_{2} / \mathrm{N}_{2} \mathrm{O} / \mathrm{Ar}$ Mixtures
}

\author{
Bo Zhang ${ }^{1}$, Hoi Dick Ng ${ }^{2 \dagger}$, Rémy Mével ${ }^{3}$, John H.S. Lee ${ }^{4}$ \\ ${ }^{1}$ Beijing Institute of Technology \\ State Key Laboratory of Explosion Science and Technology, Beijing, 100081, China \\ ${ }^{2}$ Concordia University \\ Department of Mechanical and Industrial Engineering \\ Montréal, H3G 1M8, Canada \\ ${ }^{3}$ Institut de Combustion, Aérothermique, Réactivité et Environnement (ICARE), \\ CNRS, Orléans, France \\ ${ }^{4}$ McGill University \\ Department of Mechanical Engineering, Montréal, H3A 2K6, Canada

\section{${ }^{\dagger}$ Corresponding Author} \\ Department of Mechanical and Industrial Engineering \\ Concordia University \\ 1455 de Maisonneuve Blvd. West \\ Montréal, H3G 1M8, Canada \\ e-mail: hoing@encs.concordia.ca \\ Tel.: (514) 848-2424 (ext. 3177) \\ Fax: (514) 848-3175
}

Revised manuscript submitted to International Journal of Hydrogen Energy

January, 2011 


\title{
Critical Energy for Direct Initiation of Spherical Detonations in $\mathrm{H}_{2} / \mathrm{N}_{2} \mathrm{O} / \mathrm{Ar}$ Mixtures
}

\begin{abstract}
Although the detonation phenomenon in hydrogen-nitrous oxide mixtures is a significant issue for nuclear waste storage facilities and development of propulsion materials, very limited amount of critical energy data for direct initiation - which provides a direct measure of detonability or sensitivity of an explosive mixture - is available in literature. In this study, the critical energies for direct blast initiation of spherical detonations in hydrogen-nitrous oxide-Ar mixtures obtained from laboratory experiments and theoretical predictions at different initial conditions (i.e., different initial pressure, equivalence ratio and amount of argon dilution) are reported. In the experiments, direct initiation is achieved via a spark discharge from a high voltage and low inductance capacitor and the initiation energy is estimated accordingly from the current output. Characteristic detonation cell sizes of hydrogen-nitrous oxide-Ar mixtures are estimated from chemical kinetics using a recently updated reaction mechanism. A correlation expression is developed as a function of initial pressure, argon dilution and equivalence ratio, which is fitted to provide good estimation of the experimental measured data. The direct link between cell size and critical energy for direct blast initiation is then analyzed. Good agreement is found between experimental results and theoretical predictions, which make use of the cell size estimation correlation and the semi-empirical surface energy model. The effects of the initial pressure, equivalence ratio and the amount of Ar dilution on the critical initiation energy $\mathrm{H}_{2}-\mathrm{N}_{2} \mathrm{O}$-Ar mixtures are investigated. By comparing the critical energies with those of $\mathrm{H}_{2}-\mathrm{O}_{2}-\mathrm{Ar}$ mixtures, it is shown that $\mathrm{H}_{2}-\mathrm{N}_{2} \mathrm{O}$ mixtures are more detonation sensitive with smaller initiation energies than $\mathrm{H}_{2}-\mathrm{O}_{2}$ mixtures at the same initial pressure, equivalence ratio and amount of argon dilution, except for higher diluted condition with amount of argon in the mixture above $20 \%$. Attempt is made to explain the critical energy variation and comparison between the two $\mathrm{H}_{2}-\mathrm{N}_{2} \mathrm{O}-\mathrm{Ar}$ and $\mathrm{H}_{2}-\mathrm{O}_{2}-\mathrm{Ar}$ mixtures from the induction length analysis and detonation instability consideration.
\end{abstract}

Keywords: hydrogen; nitrous oxide; direct initiation; critical energy; detonation sensitivity. 


\section{Introduction}

The significant relevance of detonation initiation study in hydrogen-nitrous oxide $\left(\mathrm{H}_{2} / \mathrm{N}_{2} \mathrm{O}\right)$ mixtures generally arises from the safety concern of detonation hazards in nuclear waste storage facilities. The potential interest in explosion studies of hydrogen-nitrous oxide mixtures also extends to the application in the propulsion materials, e.g., $\mathrm{N}_{2} \mathrm{O}$ is considered as oxidizer for rocket propulsion and the subset of the gas phase reactions in the burning of the solid propellants is often related to $\mathrm{H}_{2} / \mathrm{N}_{2} \mathrm{O}$ combustion. In many industrial applications, contaminant in fuel storage tanks, chemical and radiolytic generation of gases can create sensitive combustibles; under certain conditions the deflagration to detonation transition (DDT) or direct initiation of detonation could occur in these mixtures. Due to the high reaction sensitivity or hazardous properties of hydrogen, these issues are of particular concerns in term of safety [1-4] and had long been main focus in the field of hydrogen energy research [5-13]. In particular, several studies have indeed been performed to understand the combustion and explosion characteristics of the hydrogen-nitrous oxide mixtures, notably at CalTech [14-18], US Bureau of Mines [19] and ICARE [20-22]. From these studies, fundamental parameters such as flammability limits, detonation cell sizes, flame speeds and shock tube induction delay times data have been gathered. However, direct detonation initiation in hydrogen-nitrous oxide mixtures and those diluted with inert gas is not taken into account and has not yet been studied thoroughly for the safety concerns.

Direct initiation of detonation, in contrast to the transition from deflagration to detonation, refers to an "instantaneous" generation of a detonation wave [23]. In this mode, the detonation can be formed via the rapid deposition of a large amount of energy in a small 
volume of the combustible mixture. If a sufficient amount of energy is released by the igniter, rapid auto-ignition takes place behind the generated blast wave and the reaction-coupled shock quickly becomes a CJ detonation. For direct blast initiation, the initiation source energy is the sole parameter which governs the success or failure of the detonation initiation [24]. It thus represents an important data for the characterization of the explosives' sensitivity. The minimum energy required for the direct blast initiation of a detonation in a given explosive mixture (i.e., the critical initiation energy) has long been considered as, perhaps, the most direct means of determining an explosive sensitivity [25].

The estimation of critical energy for direct detonation initiation is of fundamental importance for the evaluation of the explosion probability in industrial processes. Despite the studies on direct detonation initiation which have been extensively carried out in the past, the available data on the critical initiation energy of direct blast initiation for hydrogen-nitrous oxide mixtures are quite limited if compared to more common mixtures such as hydrocarbon-oxygen or hydrogen-oxygen mixtures. Moreover, due to the lack of a complete quantitative theory, some empirical relationships between critical initiation energy of direct blast initiation and initial conditions (i.e., initial pressure, equivalence ratio and amount of argon dilution) for $\mathrm{H}_{2}-\mathrm{N}_{2} \mathrm{O}$ mixtures are still desirable, especially for explosion hazard assessment in industrial applications.

The purpose of this study is therefore to obtain, both experimentally and theoretically, the critical initiation energy for direct blast initiation at different initial conditions for hydrogen-nitrous oxide mixtures, undiluted and diluted with argon. The effects of the initial pressure, equivalence ratio and the amount of argon dilution on the critical initiation energy 
are studied in details. In addition, this work aims at investigating the difference in detonation sensitivity by using nitrous oxide as an oxidizer instead of oxygen by comparing the critical energy of $\mathrm{H}_{2}-\mathrm{N}_{2} \mathrm{O}$-Ar with $\mathrm{H}_{2}-\mathrm{O}_{2}$-Ar mixtures.

\section{Experimental details and chemical kinetics analysis}

\subsection{Experiment setup}

In this study, mixtures of stoichiometric $\mathrm{H}_{2}-\mathrm{N}_{2} \mathrm{O}$ at different initial pressure ranging from 70 to $200 \mathrm{kPa}$, equivalence ratio from $0.5-1.2$ and stoichiometric mixtures with the maximum percentage of Ar dilution up to $30 \%$ at atmospheric pressure condition are investigated. Mixtures of $\mathrm{H}_{2}-\mathrm{O}_{2}$-Ar at the same initial conditions are also considered for critical energy comparison. Part of the critical energy data for $\mathrm{H}_{2}-\mathrm{O}_{2}$ mixtures is obtained from the previous work [26].

Direct detonation initiation experiment is carried out in a high pressure spherical bomb. A schematic of the apparatus is given in Fig. 1. The ignition system is constructed in previous studies (see [26-28] for further details). It essentially consists of a high voltage power supply, capacitor bank, a gap-switch, a trigger module (TM-11A). At the end of this slender electrode there is a $3.5 \mathrm{~mm}$ spark gap through which the energy is delivered through the ignition circuit. The procedure to estimate the actual spark discharge energy from the ignition system is carefully detailed in authors' previous studies [26] and thus, it is only briefly described here for completeness. For a given a trace of the current function $i(t)=A e^{-\alpha \cdot t} \sin (\omega t)$ recorded on the oscilloscope, the natural frequency $\omega_{n}$ is determined using $\omega$ and $\zeta$ where $\omega=\sqrt{1 /(L C)_{\text {total }}-(R / 2 L)_{\text {total }}^{2}}=\omega_{n} \sqrt{1-\varsigma^{2}}$ and attenuation factor equal to $\alpha=R_{\text {total }} / 2 L_{\text {total }}$. The 
total circuit inductance and subsequently the total circuit resistance are then calculated from $L_{\text {total }}=1 / \omega_{n}{ }^{2} C_{\text {total }}$ and $R_{\text {total }}=2 L_{\text {total }} \alpha$ accordingly. The spark resistance $R_{\mathrm{s}}$ is determined by subtracting $R_{\text {total }}=R_{\text {circuit }}$ when the spark gap is shorted out $R_{\mathrm{s}} \approx 0$ from $R_{\text {total }}=R_{\text {circuit }}+R_{\mathrm{s}}$ when the spark is not shorted. Finally, the spark discharge energy is found by numerically integrating the square of the current multiplied by spark resistance: $E_{s}=\int_{0}^{\infty} i^{2} R_{s} d t$.

According to the authors' previous investigations [28, 29], the $1 / 4$ cycle period from the high-voltage capacitor spark discharge can be adequately used to estimate the effective energy responsible for direct initiation by spark ignition analogous to the point blast energy in the ideal case. In the experimental measurement of the critical initiation energy, the amount of initial spark energy is changed via adjusting the capacity of the capacitor or the initial voltage. For each successful and unsuccessful initiation at least 3 shots are repeated to confirm the critical energy, thus the critical energy should be somewhere inside the interval between the last successful initiation and unsuccessful initiation data points.

\subsection{Chemical Kinetics Modeling}

For the equilibrium and chemical kinetics analysis, the CJ and ZND detonation properties are computed using the Chemkin package [30]. For $\mathrm{H}_{2}-\mathrm{N}_{2} \mathrm{O}-\mathrm{Ar}$ mixtures, the reaction mechanism constructed by Mével et al. [20] is used, which has been validated with several fundamental combustion data including shock tube delay times and flame speeds [20-22]. As for $\mathrm{H}_{2}-\mathrm{O}_{2}$ mixtures, the comprehensive chemical kinetic mechanism by $\mathrm{Li}$ et al. [31] is employed, which has been used and validated in our previous study on detonation sensitivity in hydrogen-oxygen mixtures [32]. 


\section{Results and Discussion}

\section{1 $\mathrm{H}_{2}-\mathrm{N}_{2} \mathrm{O}$-Ar detonation cell size prediction}

With the availability of the detailed chemical reaction mechanism for hydrogen-nitrous oxide, the characteristic induction length can be computed by solving the one-dimensional steady-state ZND structure of a detonation and directly related to the detonation cell size by the conventional relationship $\lambda=A \cdot \Delta$. Using detonation cell size data from the Caltech detonation database [33], an empirical expression for computing the proportionality parameter $A$ has been determined. Similar to the functional form used in [21], $A$ is expressed as a function of equivalence ratio $\varphi$, argon diluent mole fraction $X_{\mathrm{Ar}}$, and ratio of initial to standard pressure $p_{1} / p_{0}$ :

$$
A=25.68 \varphi^{-0.112}\left(1-X_{\mathrm{Ar}}\right)^{-1.23}\left(\frac{p_{1}}{p_{0}}\right)^{0.016}
$$

For the above correlation, the coefficient of determination $R^{2}$ and the maximum deviation between the correlated values and the experimental data are 0.906 and $45.70 \%$, respectively. It is interesting to note that, unlike the expression obtained in [21], the present correlation results in a negative exponent (-1.23) in the argon molar fraction term. To explain this different behavior, it is important to realize that, as shown in [34] and later in this paper, the induction length $\Delta_{I}$ changes only slightly with increasing argon dilution. Although the energetic effect of argon dilution on detonation is to lower the total energy release of the mixture, which results in the decrease in detonation velocity and thus shock temperature, addition of argon causes as well an increase in the specific heat ratio $\gamma$ of the mixture, leading to the opposite effect of increasing the shock temperature. These two competing effects are approximately balanced and therefore, the shock temperature $T_{\mathrm{s}}$ does not change significantly 
with argon dilution. Since the shock temperature remains almost constant, the influence of the diluent does not significantly affect the induction length $\Delta_{I}$. However, experimentally if a combustible mixture is diluted with more amount of argon, it is generally becoming more stable and its cell size is observed to be bigger. Since the value of the term $\left(1-X_{\mathrm{Ar}}\right)$ is getting smaller with more argon dilution, to keep $A$ increasing progressively the exponent of this term correlated with argon molar fraction is thus found negative.

Fig. 2 shows the variation of cell size versus initial pressure for non-diluted $\mathrm{H}_{2}-\mathrm{N}_{2} \mathrm{O}$ mixtures. It can be seen that the predictions from the $A=f\left(\varphi, X_{\mathrm{Ar}}, p\right)$ correlation are in good agreement with Akbar et al. experimental data [17]. Fig. 3 shows the predicted cell size and other available experimental data [33] as a function of equivalence ratio for $\mathrm{H}_{2}-\mathrm{N}_{2} \mathrm{O}$ mixture at the initial pressure of $70.9 \mathrm{kPa}$. The cell width versus equivalence ratio curve has the familiar "U" shape with a minimum near stoichiometric condition. It can also be noted from Fig. 3 that, generally the correlation gives good agreement; however, at the lean side where $\varphi$ is below 0.7 , the prediction from $A=f\left(\varphi, X_{\mathrm{Ar}}, p\right)$ correlation begins to underestimate the experimental cell size. This discrepancy can perhaps be explained by the fact that near the detonability limit, very large velocity deficit and fluctuation can occur that resulted in a wide range of cell size and increased uncertainty in the measurement. Nevertheless, the correlation still gives an acceptable accuracy within a factor of two.

Fig. 4 shows the theoretical prediction and experimental measured cell sizes [35] as a function of equivalence ratio for the $\mathrm{H}_{2}-\mathrm{N}_{2} \mathrm{O}$ diluted $20 \%$ and $40 \%$ argon mixtures, respectively. Once again, taking into account the error on the cell size measurement itself, the correlation can readily estimate the cell size with acceptable accuracy. 
Based on the above validation, one can be confident that the correlation $A=f\left(\varphi, X_{\mathrm{Ar}}, p\right)$ provides a reasonable prediction of detonation cell size for $\mathrm{H}_{2}-\mathrm{N}_{2} \mathrm{O}-\mathrm{Ar}$ mixtures at various initial conditions.

\subsection{Critical initiation energy for $\mathrm{H}_{2}-\mathrm{N}_{2} \mathrm{O}$-Ar mixtures}

In order to make comparison with experimental data, critical direct initiation energy can be first approximated using the semi-empirical theory proposed by Lee et al. $[23,36]$ and it is validated to provide very good approximation $[26,27]$. It is a simple semi-empirical model that links the initiation energy with the detonation cell size. It is based on the idea that a minimum surface energy is required before a planar wave can evolve into a spherical wave without being quenched by expansion waves coming from the boundaries of the detonation wave itself. The link is therefore established based on the minimum surface energy of the critical tube to the surface area of the critical size of the minimum detonation kernel. The surface energy contained in the point blast which initiated a spherical detonation wave at the time when the wave has decayed to the $\mathrm{CJ}$ state is equivalent to the energy in the planar detonation wave in the critical tube diameter. Hence equating the minimum surface areas of both waves at criticality and using the $d_{\mathrm{c}}=13 \lambda$ rule for common hydrocarbon mixtures and the classical blast wave theory formulation [24], the critical initiation energy can be determined by:

$$
E_{c}=4 \pi \gamma p_{o} M_{C J}^{2} I\left(\frac{13 \lambda}{4}\right)^{3}=\frac{2197}{16} \pi \rho_{o} V_{C J}^{2} I \lambda^{3}
$$

where $\rho_{\mathrm{o}}$ is the initial density of the mixture, $V_{\mathrm{CJ}}$ the CJ detonation velocity, $\lambda$ the cell size and $I$ is a numerical constant from classical strong blast theory (for $\gamma=1.4, I=0.423$ ). 
It is thus suggested by Eq. 2 that detonation cell size $\lambda$ plays prominent role in determining the critical initiation energy. With the knowledge of experimentally measured or theoretically predicted cell sizes, critical initiation energy can be estimated by the combination of surface energy model and the cell size correlation introduced in section 3.1.

Critical initiation energy for $\mathrm{H}_{2}-\mathrm{N}_{2} \mathrm{O}$ mixtures at different initial conditions obtained from both experimental measurements and theoretical predictions are given in Figs. 5, 6 and 8. Fig. 5 first shows the critical energy as a function of initial pressure. Similar to common fuel-oxygen mixtures, the critical energy decreases as initial pressure increases and that the mixture becomes more detonation sensitive. From this plot, one can readily see that the theoretical prediction - which is based on Lee's surface energy model and $A=f\left(\varphi, X_{\mathrm{Ar}}, p\right)$ cell size correlation - can estimate the critical energy at each initial pressure with quite reasonable accuracy.

Fig. 6 shows the variation of experimental and predicted detonation critical energies versus equivalence ratio for $\mathrm{H}_{2}-\mathrm{N}_{2} \mathrm{O}$ mixtures at the initial pressure of $100 \mathrm{kPa}$. Both the experimental data and the theoretical prediction curves indicate that the critical initiation energy along with its equivalence ratio $\varphi$ varies in the form of typical " $U$ " shape, and the minimum of the critical initiation energy comes around $\varphi \sim 0.75$. This is in agreement with the theoretical prediction as well as the induction zone length variation obtained from chemical kinetics shown in Fig. 7 showing a minimum induction length scale around $\varphi \sim 0.8$.

An additional parameter which is worth investigating in order to gain further insight on the critical energy variation, hence the detonation sensitivity, is the detonation stability parameter $\chi$ which has been introduced from the recent stability analysis [37]. This parameter 
$\chi$ is defined by the activation energy of the induction zone multiplied by the ratio of induction zone to the exothermic heat release length, i.e.

$$
\chi=\varepsilon_{I} \frac{\Delta_{I}}{\Delta_{R}}=\varepsilon_{I} \Delta_{I} \frac{\dot{\sigma}_{\max }}{u_{C J}^{\prime}}
$$

$\varepsilon_{I}, \Delta_{R}, \dot{\sigma}_{\max }$ and $u_{C J}^{\prime}$ denote the activation energy of the induction process, main heat release zone length, maximum thermicity and CJ particle velocity in shock-attached frame, respectively [37]. It has been suggested that the detonation cellular instability or the dynamic turbulent structure of detonations can play an important role in the initiation of detonation as illustrated in the critical tube diameter problem where a detonation wave undergoes a sudden expansion into open space [24]. Unstable detonations commonly in undiluted combustible mixtures usually have high degree of instability and a successful transmission in the critical tube diameter phenomenon is characterized by local explosion centers re-initiation mechanism. A higher degree of instability resulted in the formation of these localized explosions may thus facilitate or ease the initiation or the onset of a detonation. From Fig. 7 showing the stability parameter $\chi$ variation, it is of interest to note that the detonation wave is more unstable at the lean side, i.e. the maximum value of the stability parameter $\chi$ is around $\varphi \sim 0.7$ and this appears to agree with the main observation that the minimum critical initiation energy located on the lean side $\varphi<1$.

To study the effect of inert gas dilution, resulting in the decrease of energy content and the change in thermodynamic properties of the mixtures without modifying the chemical kinetic mechanism, we look at the detonation sensitivity of the mixtures with the addition of different amounts of argon. Fig. 8 shows the critical energy for hydrogen-nitrous oxide mixtures diluted with different amount of argon. As seen from Fig. 8 that with the increasing 
amount of argon dilution, the critical initiation energy increases consequently; in other words, with more argon dilution, the mixtures tend to become less sensitive to detonation initiation. Shown in Fig. 9 is the variation of induction length scale and the stability parameter $\chi$ as a function of Ar dilution. By increasing the argon dilution, the induction zone length does not vary much $(\sim 3 \%)$. However, with more amount of Ar dilution, the stability parameter $\chi$ decreases significantly, i.e. the detonation front becomes more regular and the cellular instabilities play lesser role in the formation of a self-sustained propagating detonation, which can in turn explain the increase of critical initiation energy for direct detonation initiation.

\subsection{Critical energy comparison between $\mathrm{H}_{2}-\mathrm{N}_{2} \mathrm{O}$-Ar and $\mathrm{H}_{2}-\mathrm{O}_{2}$-Ar mixtures}

To look at the effect of the oxidizer, a series of experiments using mixtures of $\mathrm{H}_{2}-\mathrm{O}_{2}-\mathrm{Ar}$ at the same initial conditions as those with $\mathrm{H}_{2}-\mathrm{N}_{2} \mathrm{O}-\mathrm{Ar}$ mixtures are performed in order to make comparison of their critical energies and further investigate different chemical kinetic effects.

The critical energy of direct detonation initiation for stoichiometric $\mathrm{H}_{2}-\mathrm{O}_{2}$ and $\mathrm{H}_{2}-\mathrm{N}_{2} \mathrm{O}$ mixtures as a function of initial pressure are shown in Fig. 10. For the critical energy of $\mathrm{H}_{2}-\mathrm{O}_{2}$ mixtures with initial pressure lower than $100 \mathrm{kPa}$, the data from Zitoun et al. [38] are also included in the plot, where the trend follows well with the present data above $100 \mathrm{kPa}$. By comparing the critical energy of $\mathrm{H}_{2}-\mathrm{O}_{2}$ and $\mathrm{H}_{2}-\mathrm{N}_{2} \mathrm{O}$ mixtures at a same initial pressure, for example at $100 \mathrm{kPa}$, it can be seen from Fig. 10 that the critical energy of $\mathrm{H}_{2}-\mathrm{N}_{2} \mathrm{O}$ mixture is between 3.98-4.46 J; on the other hand, for $\mathrm{H}_{2}-\mathrm{O}_{2}$ mixture it is between 9.05-10.12 J obtained from this experiment and $12.5 \mathrm{~J}$ from Zitoun et al. [38]. One can notice that the critical energies for $\mathrm{H}_{2}-\mathrm{N}_{2} \mathrm{O}$ mixtures are always lower than those of $\mathrm{H}_{2}-\mathrm{O}_{2}$ mixture at the range of 
initial pressure considered here. Similar observation can be made in variation of cell size $\lambda$ with initial pressure for the two mixtures obtained in the Caltech detonation database [33] (cell sizes of stoichiometric $\mathrm{H}_{2}-\mathrm{O}_{2}$ mixture are from Denisov and Troshin [39], Lee and Matsui [40] and Manzhalei et al. [41] for the pressure range of interest in this study), which is shown in Fig. 11. As can be seen that the cell sizes for $\mathrm{H}_{2}-\mathrm{O}_{2}$, despite of the uncertainty in the measurement, are slightly larger than the $\mathrm{H}_{2}-\mathrm{N}_{2} \mathrm{O}$ mixture corresponding to each initial pressure. To further explain this critical energy comparison, Fig. 12 shows the results of induction length analysis and stability parameter variation. Results indicate that steady induction zone length scales at different initial pressures are very close for both mixtures. However, the stability parameter for $\mathrm{N}_{2} \mathrm{O}$ mixtures is almost twice that for $\mathrm{O}_{2}$ mixtures. The smaller initiation energy for $\mathrm{N}_{2} \mathrm{O}$ mixtures can thus be explained again qualitatively from the detonation instability consideration. It is worth noting that the difference in the behavior of stability parameter for both systems is due to the difference in the details of the chemical kinetics. For instance, contrary to $\mathrm{H}_{2}-\mathrm{O}_{2}$ mixtures, for which the initiation step is the hydrogen dissociation, the initiation step for $\mathrm{H}_{2}-\mathrm{N}_{2} \mathrm{O}$ mixtures is the dissociation of nitrous oxide. The additional reactions steps involved in the $\mathrm{N}_{2} \mathrm{O}$ chemistry also modify the formation and consumption in the $\mathrm{OH}$ and $\mathrm{H}$ radicals pathways, giving a difference in the chemical sensitivity of the reaction structure - hence a different degree of detonation instability - in hydrogen-nitrous oxide mixtures [21].

The critical initiation energy for $\mathrm{H}_{2}-\mathrm{N}_{2} \mathrm{O}$ and $\mathrm{H}_{2}-\mathrm{O}_{2}$ mixture at atmospheric pressure with the variation of equivalence ratio are shown in Fig. 13. The critical energy for $\mathrm{H}_{2}-\mathrm{O}_{2}$ mixture is from the experimental measurement of Litchfield et al. [42]. Both curves of critical energy 
variation with equivalence ratio for $\mathrm{H}_{2}-\mathrm{O}_{2}$ and $\mathrm{H}_{2}-\mathrm{N}_{2} \mathrm{O}$ mixtures are again described by the typical "U" shape behavior; and the minimum critical energy for these mixtures is similar, which occurs around $\varphi=0.8$. However, the energy value of $\mathrm{H}_{2}-\mathrm{O}_{2}$ is significantly bigger than that of $\mathrm{H}_{2}-\mathrm{N}_{2} \mathrm{O}$ mixture when the same equivalence ratio is considered. This observation is in good agreement with both the induction length and stability analysis (see Fig. 14). The difference in induction length for both mixtures appears to be minimal; and $\mathrm{H}_{2}-\mathrm{O}_{2}$ mixtures are generally more stable, characterized by lower values of $\chi$ than $\mathrm{H}_{2}-\mathrm{N}_{2} \mathrm{O}$ mixtures.

This study looks at finally the critical initiation energy for both stoichiometric $\mathrm{H}_{2}-\mathrm{O}_{2}$ and stoichiometric $\mathrm{H}_{2}-\mathrm{N}_{2} \mathrm{O}$ mixtures diluted with different amount of argon and results are shown in Fig. 15. It is interesting to note that although for undiluted case the critical energy for $\mathrm{H}_{2}-\mathrm{O}_{2}$ is higher than that for $\mathrm{H}_{2}-\mathrm{N}_{2} \mathrm{O}$ mixture, with an increasing amount of argon dilution the critical energy for $\mathrm{H}_{2}-\mathrm{O}_{2}$-Ar mixture increases very slightly, yet for $\mathrm{H}_{2}-\mathrm{N}_{2} \mathrm{O}$-Ar mixture the increase of critical energy is very rapid. There appears a cross-over in the critical energy variation between these two mixtures around $20 \% \mathrm{Ar}$ dilution. In other word, for further increase of argon dilution over $20 \%$, the critical energy for $\mathrm{H}_{2}-\mathrm{N}_{2} \mathrm{O}-\mathrm{Ar}$ becomes in turn bigger than that of $\mathrm{H}_{2}-\mathrm{O}_{2}$-Ar mixture. To understand this observation, Fig. 16 first shows that detonation cell size as a function of argon dilution for stoichiometric $\mathrm{H}_{2}-\mathrm{O}_{2}-\mathrm{Ar}$ and $\mathrm{H}_{2}-\mathrm{N}_{2} \mathrm{O}-\mathrm{Ar}$ mixtures. For $\mathrm{H}_{2}-\mathrm{O}_{2}-\mathrm{Ar}$ mixture, the cell sizes are obtained using the theoretical prediction based on Ng's model [32] with the chemical kinetic mechanism from Li et al. [31]. The experimental data are extracted from Kumar [43], Denisov and Troshin [39], Desbordes et al. [44] and Manzhalei et al. [41]. Both experimental and theoretical results shows a general trend for $\mathrm{H}_{2}-\mathrm{O}_{2}$ diluted with $\mathrm{Ar}$ that with increasing argon dilution, the cell size does 
not increases significantly until an amount of argon dilution up to $70 \%$. For the cell size values of stoichiometric $\mathrm{H}_{2}-\mathrm{N}_{2} \mathrm{O}$ diluted with different amount of argon, there is no experimentally measured data available at atmospheric pressure. Hence, the cell size correlation $A=f\left(\varphi, X_{\mathrm{Ar}}, p\right)$ validated in section 3.1 is used for the estimation. The theoretical prediction curve shows that the increase in cell size is much steeper than that of $\mathrm{H}_{2}-\mathrm{O}_{2}$ mixture with the increase of Ar dilution and thus, this can result in faster increase of critical energy as Ar \% increases for $\mathrm{H}_{2}-\mathrm{N}_{2} \mathrm{O}-\mathrm{Ar}$ as observed in the experiment. It is worth nothing that above $20 \%$ Ar dilution, the cell size $\mathrm{H}_{2}-\mathrm{N}_{2} \mathrm{O}$-Ar becomes significantly larger than that of $\mathrm{H}_{2}-\mathrm{O}_{2}-\mathrm{Ar}$, resulted in much higher initiation energy for direct initiation.

Similarly from the induction length and stability analysis, $\mathrm{H}_{2}-\mathrm{N}_{2} \mathrm{O}$ mixtures have always a slightly larger induction length than that in $\mathrm{H}_{2}-\mathrm{O}_{2}$ mixtures (see Fig. 17). However, at the undiluted condition, the $\mathrm{H}_{2} / \mathrm{N}_{2} \mathrm{O}$ is more unstable with high value of stability parameter $\chi$ and that the formation is dominantly influenced by the instability effect. However, as the argon dilution increases, the rate of decrease of stability parameter in $\mathrm{H}_{2}-\mathrm{N}_{2} \mathrm{O}$ mixtures is relatively faster than that of the $\mathrm{H}_{2}-\mathrm{O}_{2}$ mixtures, this in turn causes the critical energy to increase faster for $\mathrm{H}_{2}-\mathrm{N}_{2} \mathrm{O}$ mixtures than $\mathrm{H}_{2}-\mathrm{O}_{2}$ as \% Ar dilution increases. Once the degree of instability of both $\mathrm{N}_{2} \mathrm{O}$ and $\mathrm{O}_{2}$ mixtures becomes closer and together with a relatively larger induction zone length in the $\mathrm{N}_{2} \mathrm{O}$ case, it results in the cross-over around $20 \%$ Ar dilution.

\section{Concluding Remarks}

In this study, critical energies for direct blast initiation of spherical detonations in $\mathrm{H}_{2}-\mathrm{N}_{2} \mathrm{O}-\mathrm{Ar}$ mixtures had been measured at different initial pressure ranging from 70 to $200 \mathrm{kPa}$, for 
equivalence ratio between 0.5 and 1.2 and amount of argon dilution up to $30 \%$. To assess the detonation sensitivity of $\mathrm{H}_{2}-\mathrm{N}_{2} \mathrm{O}-\mathrm{Ar}$ mixtures, the energy results are also compared with those of $\mathrm{H}_{2}-\mathrm{O}_{2}$-Ar mixtures at the same initial conditions.

Using a recently updated chemical kinetic mechanism and available experimental data from literature, an improved correlation for $\mathrm{H}_{2}-\mathrm{N}_{2} \mathrm{O}-\mathrm{Ar}$ detonation cell size prediction $\left(\lambda=25.68 \varphi^{-0.112}\left(1-X_{\mathrm{Ar}}\right)^{-1.23}\left(\frac{p_{1}}{p_{0}}\right)^{0.016} \cdot \Delta_{I}\right)$ is developed. Combining this correlation function with Lee's surface energy model, the critical energy for direct initiation can be estimated and results show a very good agreement between the theoretical predictions with those measured experimentally in this study.

The effects of initial pressure, equivalence ratio and amount of argon dilution on the critical initiation energy of $\mathrm{H}_{2}-\mathrm{O}_{2}-\mathrm{Ar}$ and $\mathrm{H}_{2}-\mathrm{N}_{2} \mathrm{O}-\mathrm{Ar}$ mixtures are then investigated. It is found that the critical initial energies for $\mathrm{H}_{2}-\mathrm{N}_{2} \mathrm{O}-\mathrm{Ar}$ mixtures are always smaller than those of $\mathrm{H}_{2}-\mathrm{O}_{2}-\mathrm{Ar}$ mixtures at the same initial pressure and equivalence ratio. However, the critical energy increases steeper for $\mathrm{H}_{2}-\mathrm{N}_{2} \mathrm{O}$ than $\mathrm{H}_{2}-\mathrm{O}_{2}$ mixture with the increasing amount of argon dilution; very close critical energy and eventually a cross-over is found when the dilution is above $20 \%$ argon in both mixtures. To understand the difference in critical initiation energy between these two mixtures, analysis using the induction zone length and instability parameter $\chi$ is considered. Results show that detonation instability can play a prominent role in the initiation, as in the detonation propagation, and unstable detonation characterized by high instability parameter $\chi$ tends to have smaller critical initiation energy. This thus suggests that the development of a more thorough model should take into account carefully the effect of detonation instability in the prediction of any detonation dynamic parameter. 
In conclusion, it appears from the present study that the critical energy for the mixture of nitrous oxide as a oxidizer mixed with hydrogen is not higher than of oxygen when initiated a detonation at the same initial pressure, equivalence ratio and amount of argon dilution, with the only exception when argon dilution is above $20 \%$ where there is a change in the detonation stability.

\section{Acknowledgments}

BZ thanks the Chinese Scholarship Council (CSC) for the granting of a fellowship for research at McGill University. This work is supported by the Natural Sciences and Engineering Research Council of Canada (NSERC). 


\section{References}

1. Hord J. Is hydrogen a safe fuel? Int J Hydrogen Energy 1978;3(2):157-176.

2. Reider R, Edeskuty FJ. Hydrogen safety problems. Int J Hydrogen Energy 1979;4:41-45.

3. Eichert H, Fischer M. Combustion-related safety aspects of hydrogen in energy applications. Int J Hydrogen Energy 1986;11(2):117-124.

4. Fischer M. Safety aspects of hydrogen combustion in hydrogen energy systems. Int J Hydrogen Energy 1986;11(9):593-601.

5. Beauvais R, Mayinger F, Strube G. Turbulent flame acceleration-mechanisms and significance for safety considerations. Int J Hydrogen Energy 1994;19(8):701-708.

6. Kratzel T, Pantow E, Eichert H. Modelling of hydrogen combustion: Turbulent flame acceleration and detonation. Int J Hydrogen Energy 1996;21(5):407-414.

7. Rigas F, Sklavounos S. Evaluation of hazards associated with hydrogen storage facilities. Int J Hydrogen Energy 2005;30:1501-1510.

8. Groethe M, Merilo E, Colton J, Chiba S, Sato Y, Iwabuchi H. Large-scale hydrogen deflagrations and detonations. Int J Hydrogen Energy 2007;32(13):2125-2133.

9. Zbikowski M, Makarov D, Molkov V. LES model of large scale hydrogen-air planar detonations: Verification by the ZND theory. Int J Hydrogen Energy 2008;33: 4884-4892.

10. Bédard-Tremblay L, Fang L, Melguizo-Gavilanes J, Bauwens L, Finstad PHE, Cheng Z, Tchouvelev AV. Simulation of detonation after an accidental hydrogen release in enclosed environments. Int J Hydrogen Energy 2009;34:5894-5901.

11. Petukhov VA, Naboko IM, Fortov VE. Explosion hazard of hydrogen-air mixtures in the large volumes. Int J Hydrogen Energy 2009;34(14):5924-5931.

12. Teodorczyk A, Drobniak P, Dabkowski A. Fast turbulent deflagration and DDT of hydrogen-air mixtures in small obstructed channel. Int $\mathbf{J}$ Hydrogen Energy 2009;34(14):5887-5893.

13. Soury H, Mazaheri K. Utilizing unsteady curved detonation analysis and detailed kinetics to study the direct initiation of detonation in $\mathrm{H}_{2}-\mathrm{O}_{2}$ and $\mathrm{H}_{2}-$ Air mixtures. Int J Hydrogen Energy 2009;34(24):9847-9856.

14. Kaneshige M, Schultz E, Pfahl UJ, Shepherd JE, Akbar R. Detonations in mixtures containing nitrous oxide. 22nd Int Sym Shock Waves, London, UK, July 18-23; 1999.

15. Pfahl U, Ross M, Shepherd JE. Flammability limits, ignition energy, and flame speeds in $\mathrm{H}_{2}-\mathrm{CH}_{4}-\mathrm{NH}_{3}-\mathrm{N}_{2} \mathrm{O}-\mathrm{O}_{2}-\mathrm{N}_{2}$ mixtures. Combust Flame 2000;123:140-58.

16. Pfahl U, Schultz E, Shepherd JE. Detonation cell width measurements for $\mathrm{H}_{2}-\mathrm{N}_{2} \mathrm{O}-\mathrm{N}_{2}-\mathrm{O}_{2}-\mathrm{CH}_{4}-\mathrm{NH}_{3}$ mixtures. GALCIT Technical Report FM-98-5; 1998. 
17. Akbar R, Kaneshige M, Schultz E, Shepherd JE. Detonations in $\mathrm{H}_{2}-\mathrm{N}_{2} \mathrm{O}-\mathrm{CH}_{4}-\mathrm{NH}_{3}-\mathrm{O}_{2}-\mathrm{N}_{2}$ mixtures. GALCIT Technical Report FM-97-3; 1997.

18. Ross M, Shepherd JE. Lean combustion characteristics of hydrogen-nitrous oxide-ammonia mixtures in air. GALCIT Technical Report FM-96-4; 1996.

19. Cashdollar K, Hertzberg M, Zlochower I, Lucci C, Grenn G, Thomas R. Laboratory flammability studies of mixtures of hydrogen, nitrous oxide, and air. Technical Report WHC-SD-WMES-219. Pittsbrugh Research Center; 1992.

20. Mével R, Javoy S, Lafosse F, Chaumeix N, Dupré G, Paillard C.E. Hydrogen-nitrous oxide delay time experimental shock tube and kinetic modelling study. Proc Combust Inst 2009;32:359-66.

21. Mével R, Lafosse F, Catoire L, Chaumeix N, Dupré G, Paillard C-E. Induction delay times and detonation cell size prediction of hydrogen-nitrous oxide-diluent mixtures. Combust Sci Tech 2008;180:1858-1875.

22. Mével R, Lafosse F, Chaumeix N, Dupré G, Paillard C-E. Spherical expanding flames in $\mathrm{H}_{2}-\mathrm{N}_{2} \mathrm{O}-\mathrm{Ar}$ mixtures: flame speed measurement and kinetic modeling. Int J Hydrogen Energy 2009;34(21):9007-9018.

23. Lee JH. Initiation of gaseous detonation. Ann Rev Phys Chem 1977;28:75-104.

24. Lee JHS. Dynamic parameters of gaseous detonations. Ann Rev Fluids Mech 1984;16:311-36.

25. Matsui H, Lee JHS. On the measure of the relative detonation hazards of gaseous fuel-oxygen and air mixture. Proc Combust Inst 1978;17:1269.

26. Kamenskihs V, Ng HD, Lee JHS. Measurement of critical energy for direct initiation of spherical detonations in high-pressure $\mathrm{H}_{2}-\mathrm{O}_{2}$ mixtures. Combust Flame 2010;157(9): 1795-1799.

27. Zhang B, Kamenskihs V, Ng HD, Lee JHS. Direct blast initiation of spherical gaseous detonation in highly argon diluted mixtures. Proc Combust Inst 2010;33(2):2265-2271.

28. Zhang B, Ng HD, and Lee JHS. Measurement of effective blast energy for direct initiation of spherical gaseous detonations from high-voltage spark discharge. Submitted to Shock Waves Journal 2010 (SHOC381).

29. Knystautas R, Lee JHS. On the effective energy for direct initiation of detonations. Combust Flame 1976;27:221-228.

30. Kee RJ, Rupley FM, Miller JA. Chemkin-II:AFortran Chemical Kinetics Package for the Analysis of Gas-Phase Chemical Kinetics. Sandia National Laboratories Report 1989; SAND89-8009.

31. Li J, Zhao ZW, Kazakov A, Dryer FL. An updated comprehensive kinetic model of hydrogen combustion. Int J Chem Kinet 2004;36:566-75. 
32. $\mathrm{Ng} \mathrm{HD}, \mathrm{Ju}$ Y, Lee JHS. Assessment of detonation hazards in high-pressure hydrogen storage from chemical sensitivity analysis. Int J Hydrogen Energy 2007;32(1):93-99.

33. Kaneshige M, Shepherd JE. Detonation database, GALCIT Technical Report FM97-8, _http://www.galcit.caltech.edu/detn_db/html/_, 1997.

34. Radulescu MI, Ng HD, Varatharajan B, Lee JHS. The effect of argon dilution on the stability of acetylene-oxygen detonations. Proc Combust Inst 2002;29:2825-2831.

35. Mével R. Etude de mécanismes cinétiques et des propriétés explosives des mélanges hydrogène-protoxyde d'azote et silane-protoxyde d'azote: Application à la sécurité industrielle. University of Orléans, 2009

36. Lee JHS, Knystautas R, Guirao CM. The link between cell size, critical tube diameter, initiation energy and detonability limits. In: J.H.S. Lee, C.M. Guirao (Eds.), Fuel-Air Explosions, University of Waterloo Press 1982; 157-187.

37. Ng HD, Radulescu MI, Higgins AJ, Nikiforakis N, Lee JHS. Numerical investigation of the instability for one-dimensional Chapman-Jouguet detonations with chain-branching kinetics. Combust Theory Model 2005;9(3):385-401.

38. Zitoun R, Desbordes D, Guerraud C, Deshaies B. Direct initiation of detonation in cryogenic gaseous $\mathrm{H}_{2}-\mathrm{O}_{2}$ mixture. Shock Waves 1995;4(6):331-337.

39. Denisov YN, Troshin YK. Structure of gaseous detonation in tubes. Sov Phys Tech Phys 1960; 5(4):419-431.

40. Lee JH, Matsui H. A comparison of the critical energies for direct initiation of spherical detonation in acetylene-oxygen mixtures. Combust Flame 1977;28(1):61-66.

41. Manzhalei VI, Mitrofanov VV, Subbotin VA. Measurement of inhomogeneities of a detonation front in gas mixtures at elevated pressures. Combust Explos Shock Waves (USSR) 1974;10(1):89-95.

42. Litchfield EL, Hay MH, Forshey DR. Direct electrical initiation of freely expanding gaseous detonation waves. Proc Combust Proc 1962;9:282-286.

43. Kumar RK. Detonation cell widths in hydrogen-oxygen-diluent mixtures. Combust Flame 1990;80(2):157-169.

44. Desbordes D, Guerraud C, Hamada L, Presles HN. Failure of the classical dynamic parameters relationships in highly regular cellular detonation systems. Prog Astronaut Aeronaut 1993;153:347-359. 


\section{Figure Captions}

Fig. 1. Schematic of the experimental setup.

Fig. 2. Experimental and predicted detonation cell size versus initial pressure for stoichiometric $\mathrm{H}_{2}-\mathrm{N}_{2} \mathrm{O}$ mixtures $\left(p_{0}=10-100 \mathrm{kPa} ; T_{\mathrm{o}}=295 \mathrm{~K}\right)$.

Fig. 3. Experimental and predicted detonation cell size for $\mathrm{H}_{2}-\mathrm{N}_{2} \mathrm{O}$ mixtures as a function of equivalence ratio at the initial pressure $p_{0}=70.9 \mathrm{kPa}$.

Fig. 4. Experimental and predicted detonation cell size as a function of equivalence ratio for $\mathrm{H}_{2}-\mathrm{N}_{2} \mathrm{O}$ diluted with $20 \%$ and $40 \%$ argon mixtures $\left(p_{0}=10 \mathrm{kPa}\right)$.

Fig. 5. Critical energy obtained from experiment and theoretical prediction as a function of initial pressure for stoichiometric $\mathrm{H}_{2}-\mathrm{N}_{2} \mathrm{O}$ mixtures.

Fig. 6. Critical energy obtained from experiment and theoretical prediction as a function of equivalence ratio for $\mathrm{H}_{2}-\mathrm{N}_{2} \mathrm{O}$ mixtures $\left(p_{0}=100 \mathrm{kPa}\right)$.

Fig. 7. Induction length and stability parameter $\chi$ as a function of equivalence ratio for $\mathrm{H}_{2}-\mathrm{N}_{2} \mathrm{O}$ mixtures.

Fig. 8. Critical energy obtained from experiment and theoretical prediction as a function of amount of argon dilution for stoichiometric $\mathrm{H}_{2}-\mathrm{N}_{2} \mathrm{O}$ mixture $\left(p_{0}=100 \mathrm{kPa}\right)$.

Fig. 9. Induction length and stability parameter $\chi$ as a function of argon dilution for $\mathrm{H}_{2}-\mathrm{N}_{2} \mathrm{O}$ mixtures.

Fig. 10. Critical energy as a function of initial pressure for stoichiometric $\mathrm{H}_{2}-\mathrm{N}_{2} \mathrm{O}$ and $\mathrm{H}_{2}-\mathrm{O}_{2}$ mixtures.

Fig. 11. Detonation cell size as a function of initial pressure for stoichiometic $\mathrm{H}_{2}-\mathrm{N}_{2} \mathrm{O}$ and $\mathrm{H}_{2}-\mathrm{O}_{2}$ mixtures.

Fig. 12. Induction length and stability parameter $\chi$ as a function of initial pressure for stoichiometic $\mathrm{H}_{2}-\mathrm{N}_{2} \mathrm{O}$ and $\mathrm{H}_{2}-\mathrm{O}_{2}$ mixtures.

Fig. 13. Critical energy as a function of equivalence ratio for $\mathrm{H}_{2}-\mathrm{N}_{2} \mathrm{O}$ and $\mathrm{H}_{2}-\mathrm{O}_{2}$ mixtures at the initial pressure of $p_{0}=100 \mathrm{kPa}$.

Fig. 14. Induction length and stability parameter $\chi$ as a function of equivalence ratio of both a) $\mathrm{H}_{2}-\mathrm{N}_{2} \mathrm{O}$ and b) $\mathrm{H}_{2}-\mathrm{O}_{2}$ mixtures.

Fig. 15. Critical energy as a function of $\%$ argon dilution for $\mathrm{H}_{2}-\mathrm{N}_{2} \mathrm{O}$ and $\mathrm{H}_{2}-\mathrm{O}_{2}$ mixtures at the initial pressure of $p_{0}=100 \mathrm{kPa}$.

Fig. 16. Detonation cell size as a function of different amount argon dilution for stoichiometic $\mathrm{H}_{2}-\mathrm{N}_{2} \mathrm{O}$ and $\mathrm{H}_{2}-\mathrm{O}_{2}$ mixture $\left(p_{0}=100 \mathrm{kPa}\right)$.

Fig. 17. Induction length and stability parameter $\chi$ as a function of $\%$ Ar dilution of both $\mathrm{H}_{2}-\mathrm{N}_{2} \mathrm{O}$ and $\mathrm{H}_{2}-\mathrm{O}_{2}$ mixtures. 


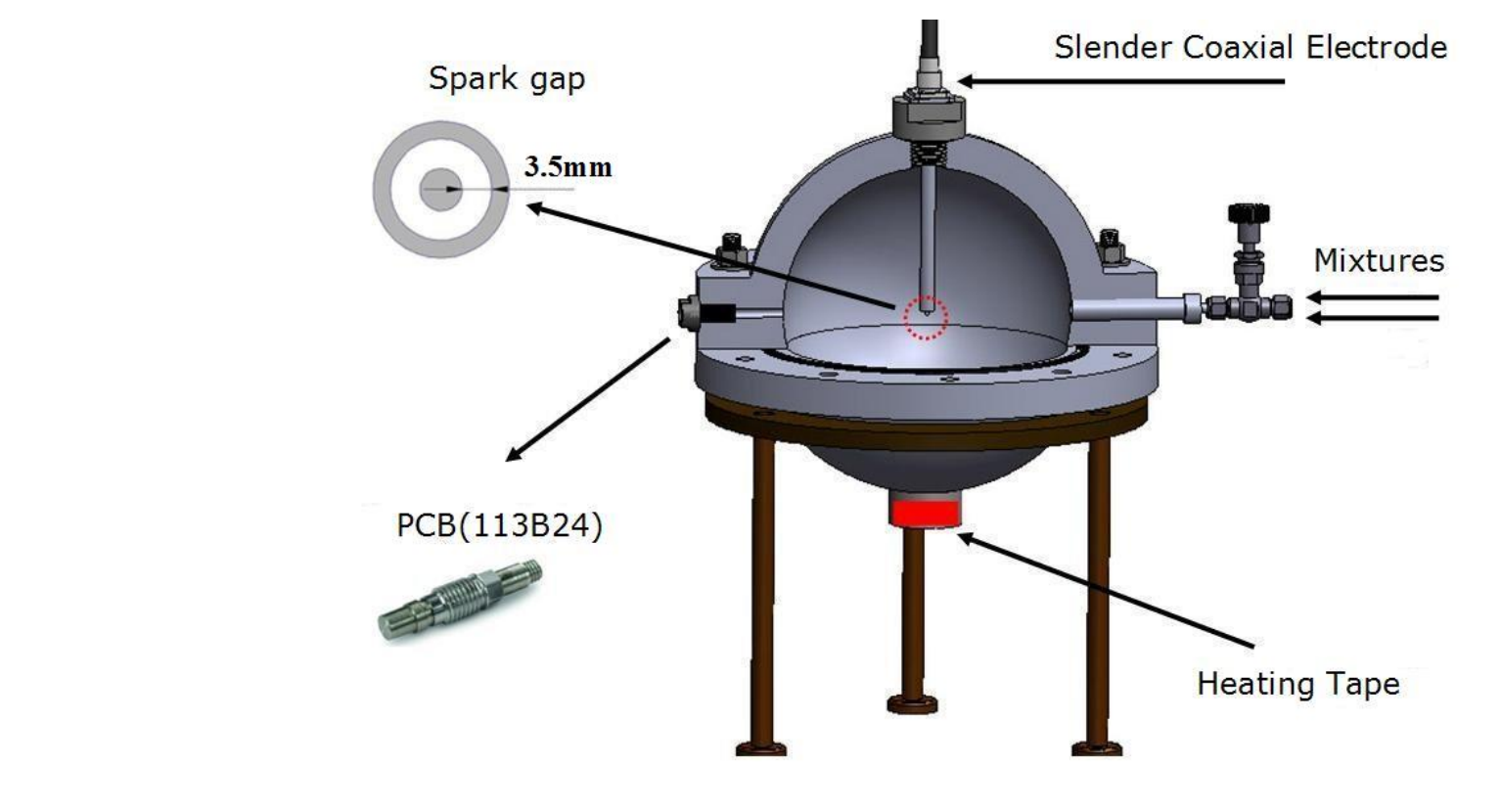

Fig. 1.

Fig. 1.

Fure1

iig. 1. 


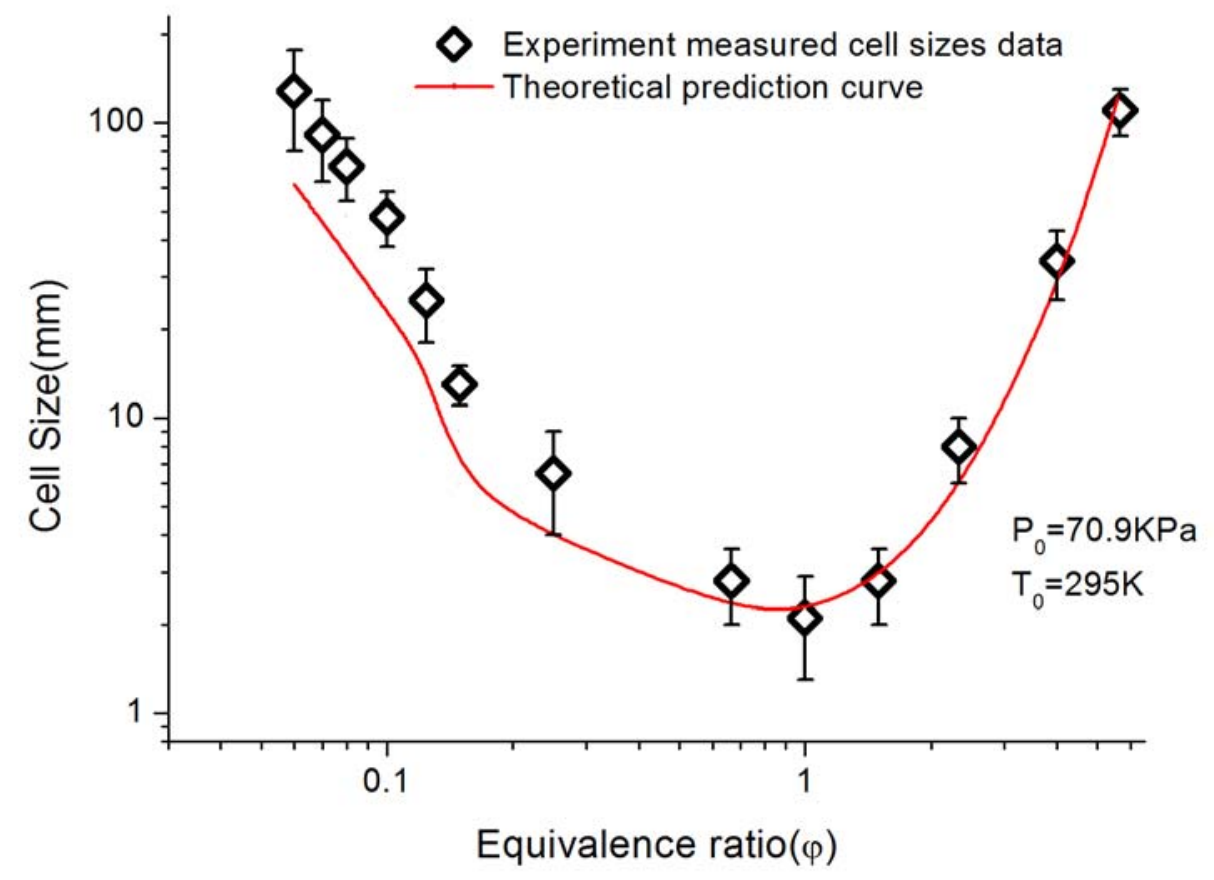

Fig. 3.

Figure3 


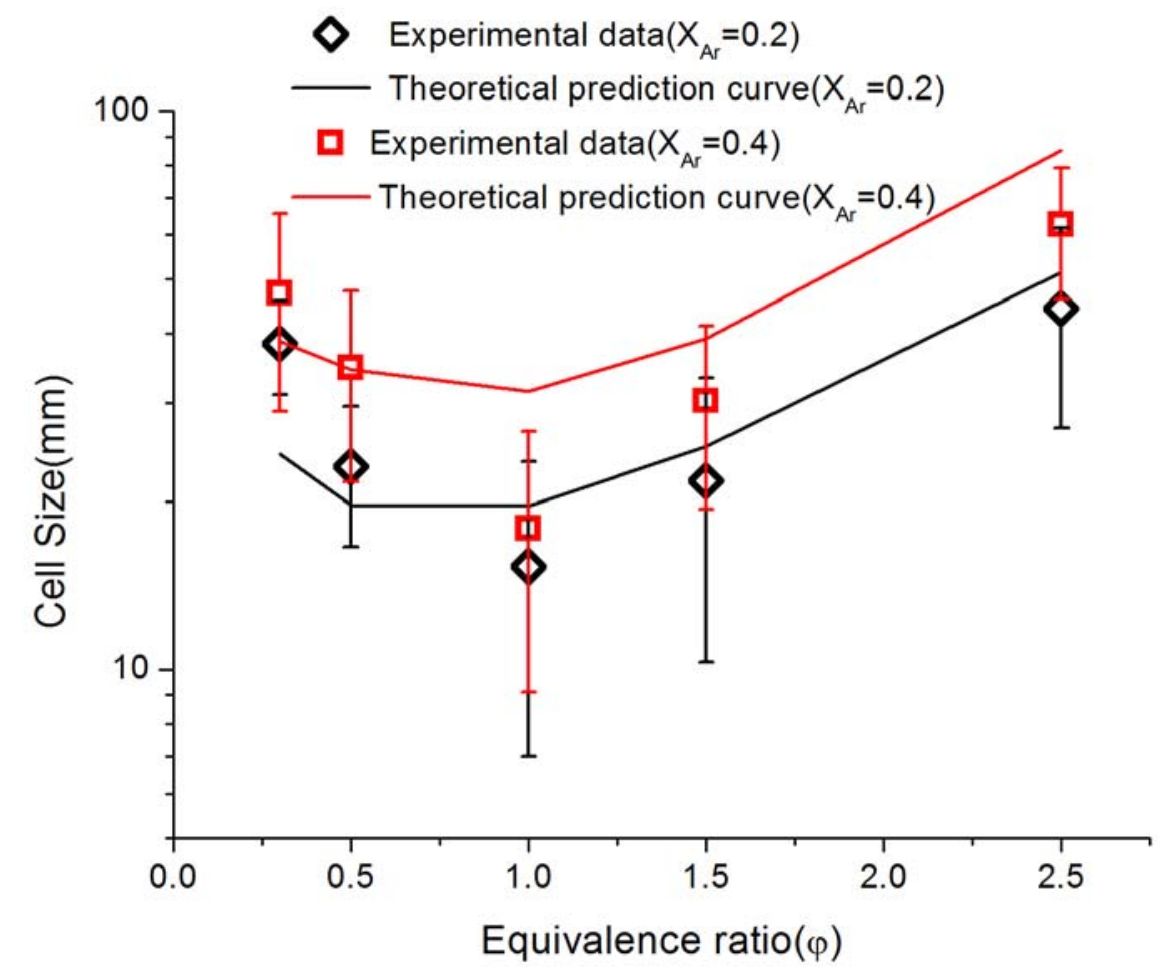

Fig. 4. 


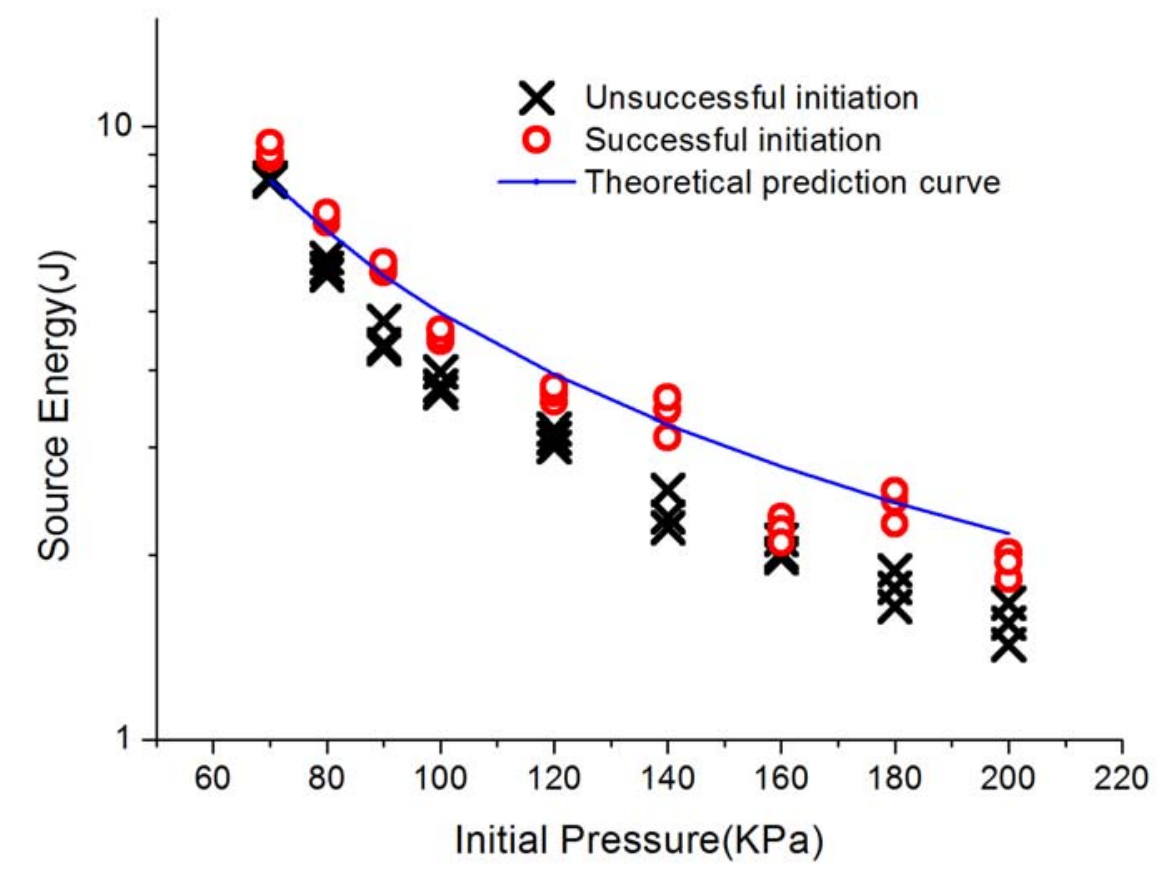

Fig. 5.

Figure5 


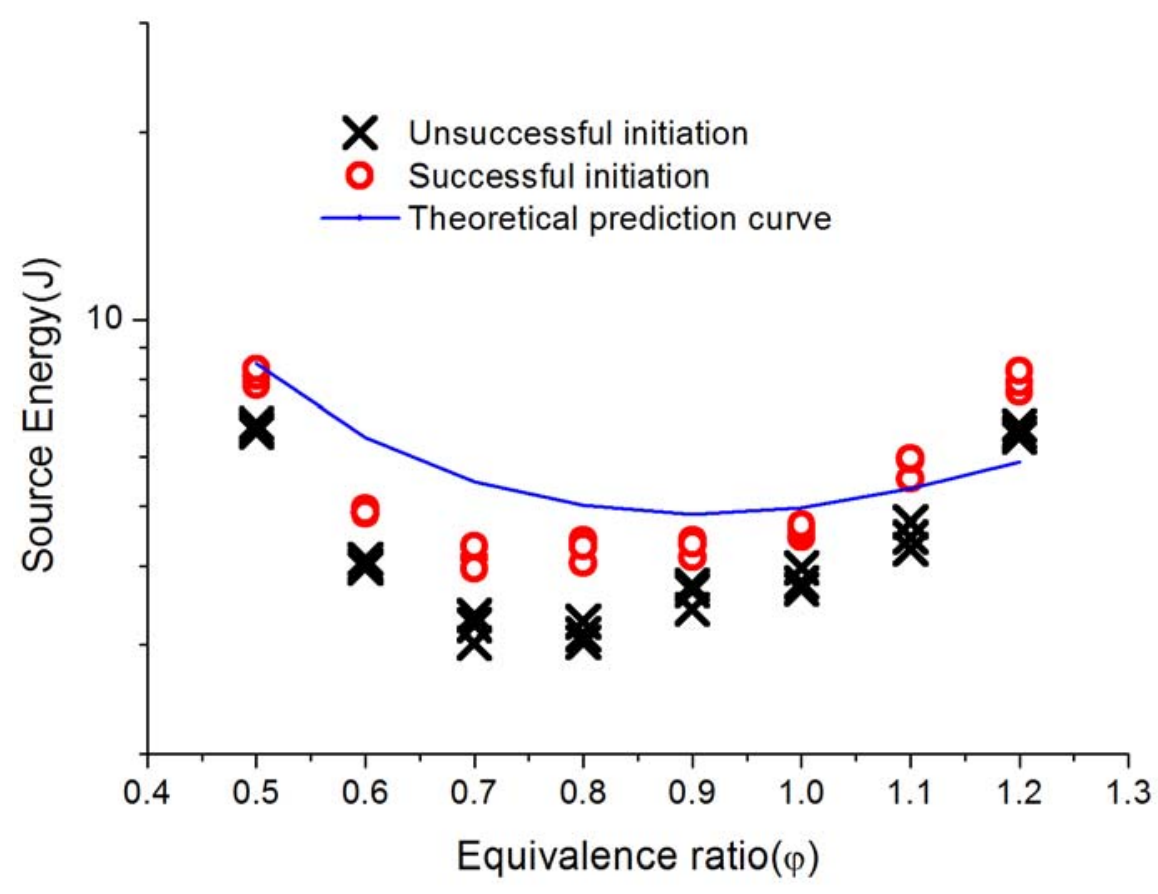

Fig. 6.

Figure6 


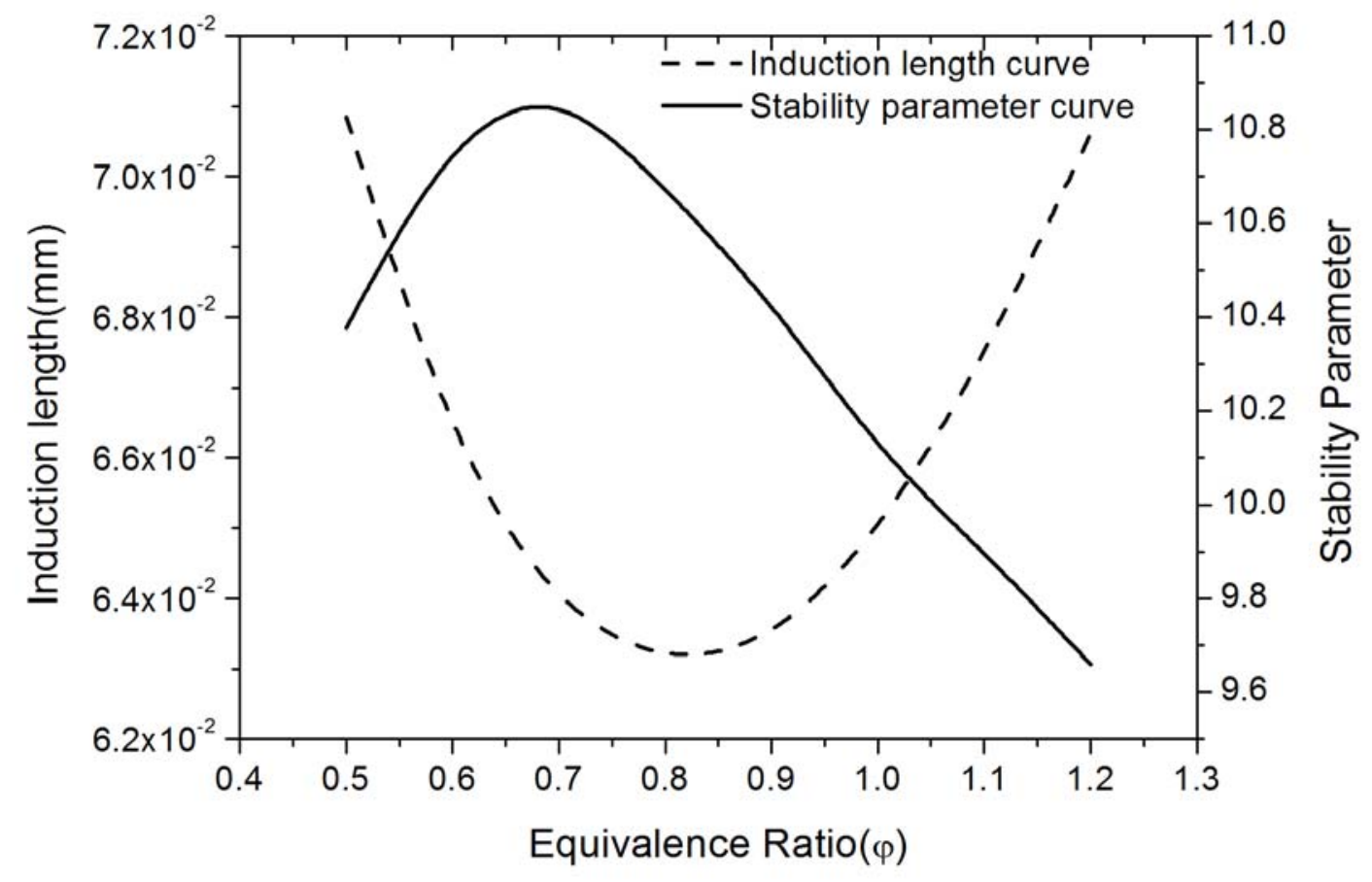

Fig. 7. 


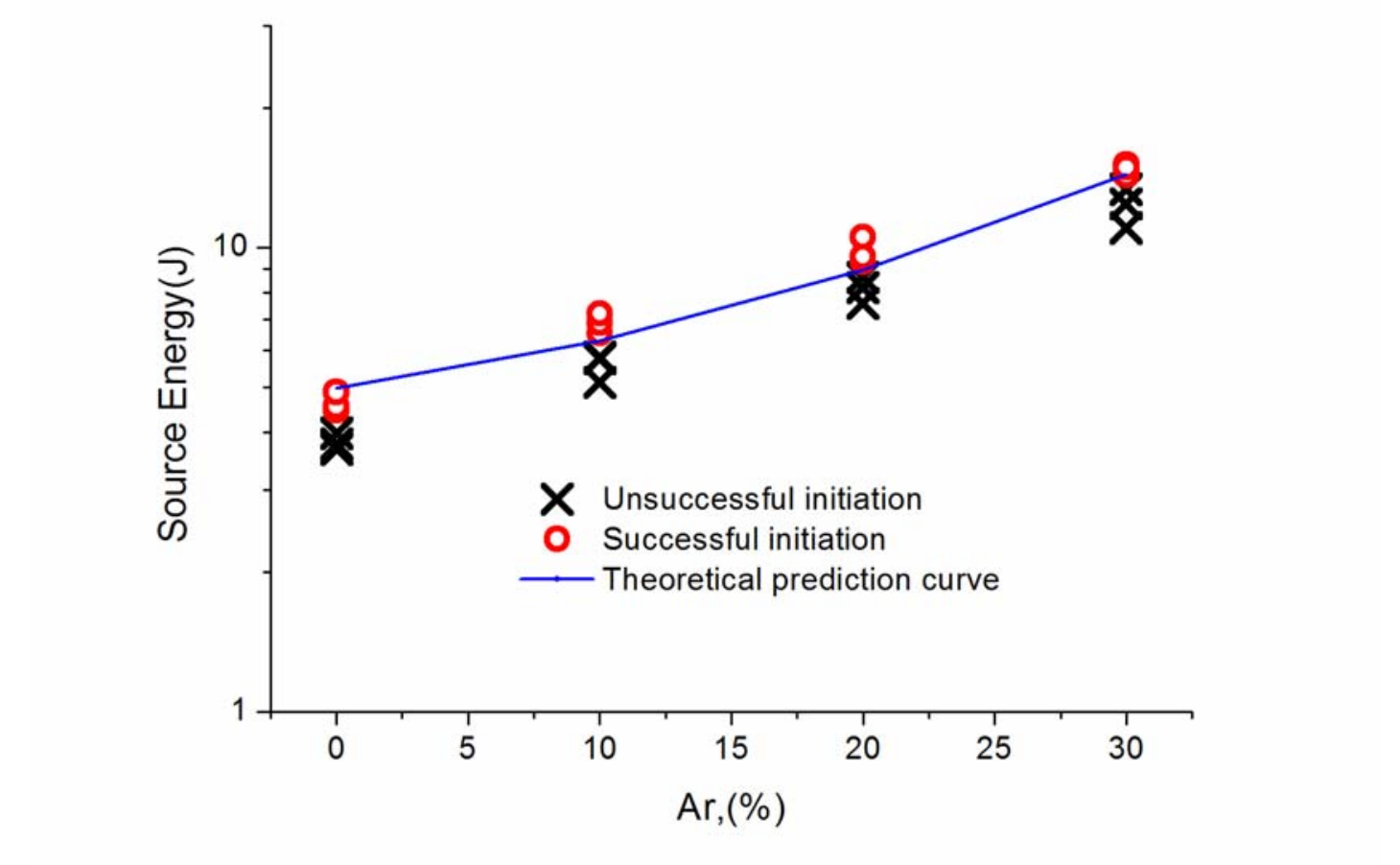

Fig. 8.

Figure8

Fig. 8.

\section{Figure8}

8.

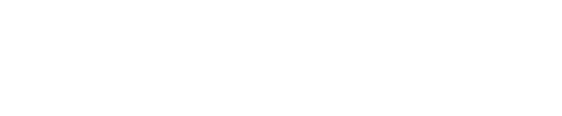

The

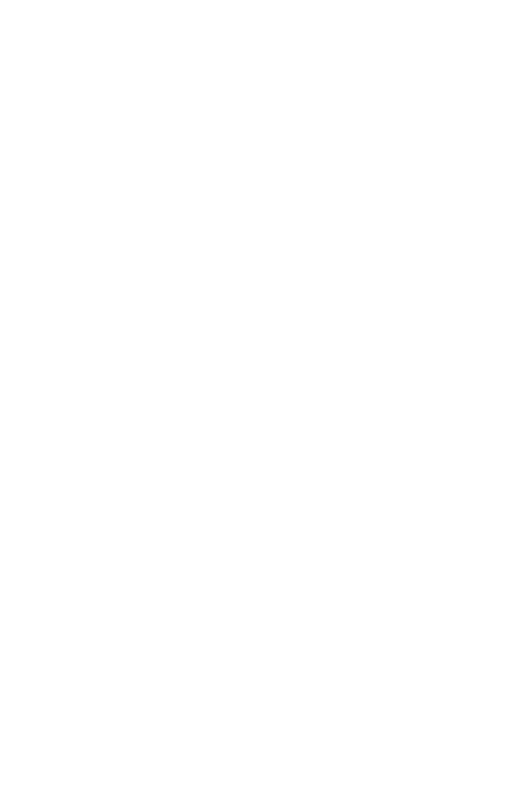




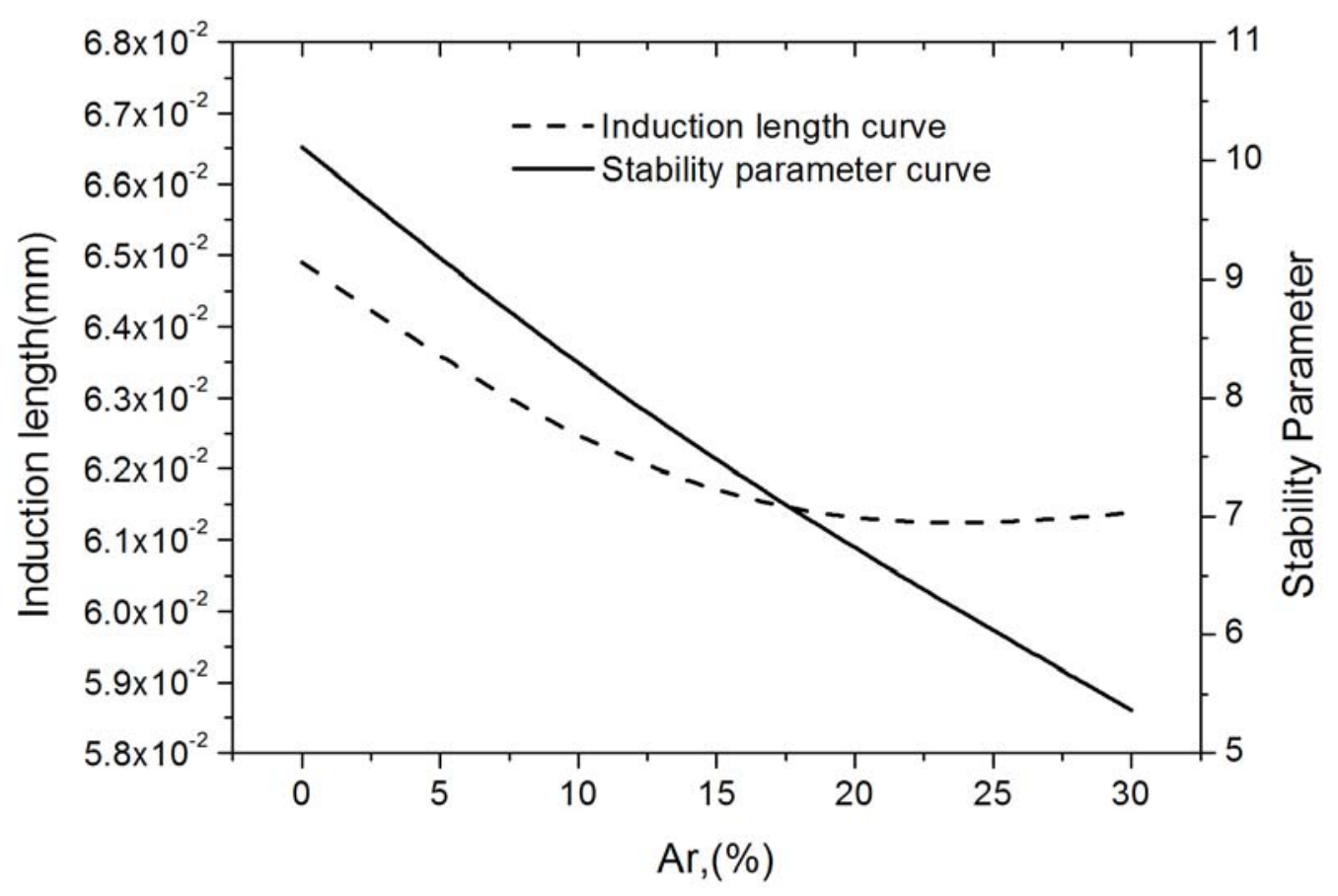

Fig. 9. 


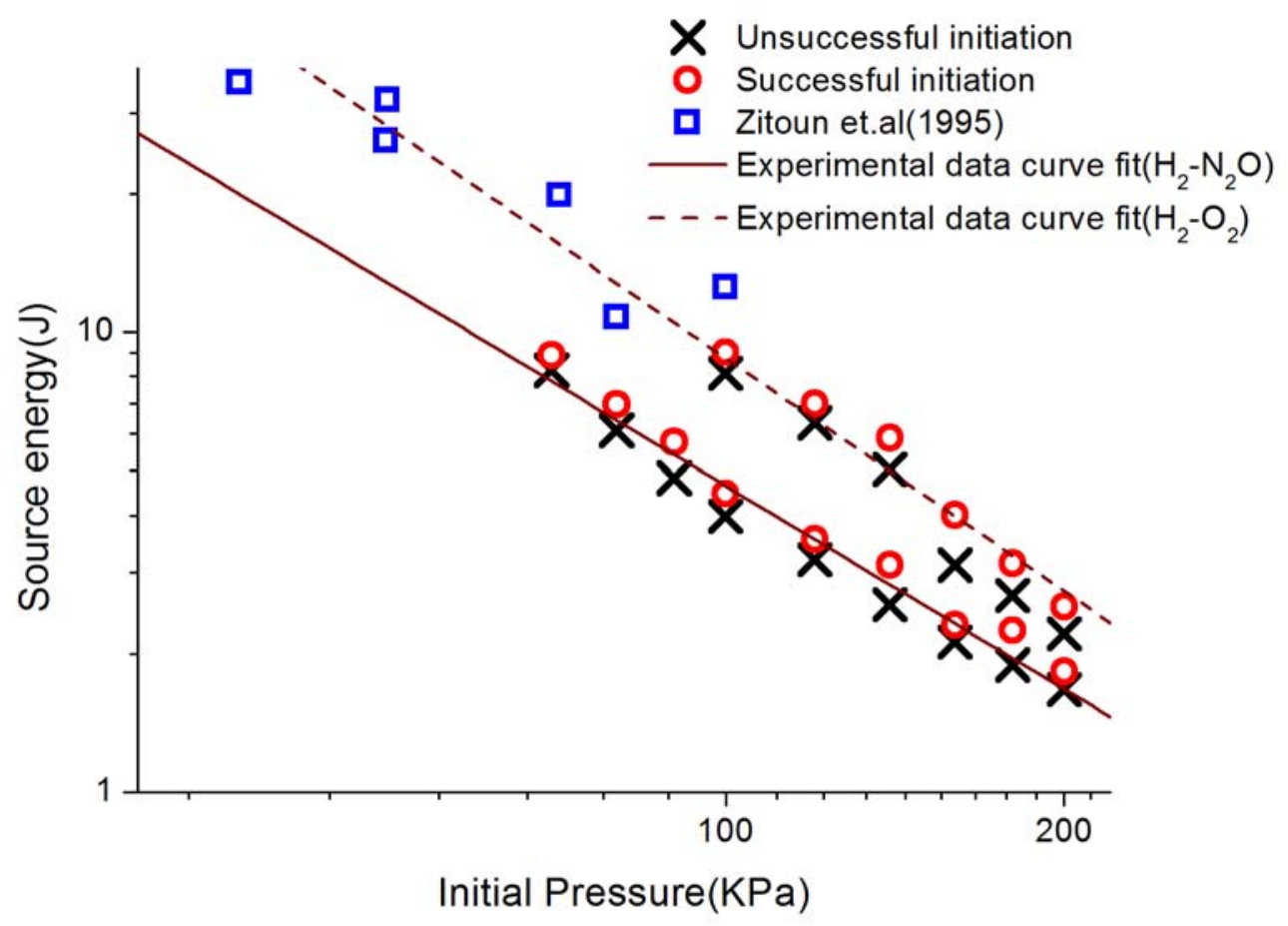

Fig. 10. 


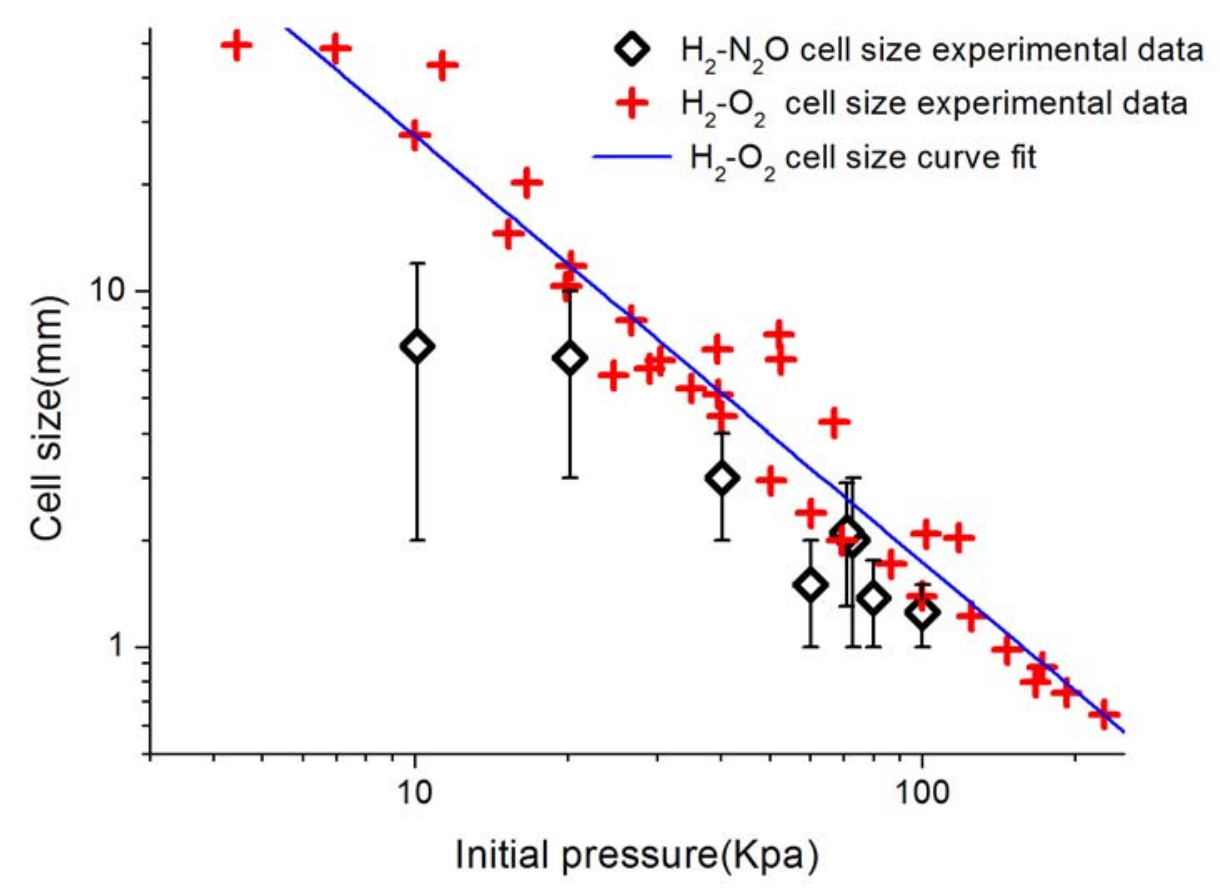

Fig. 11.

Figure11 

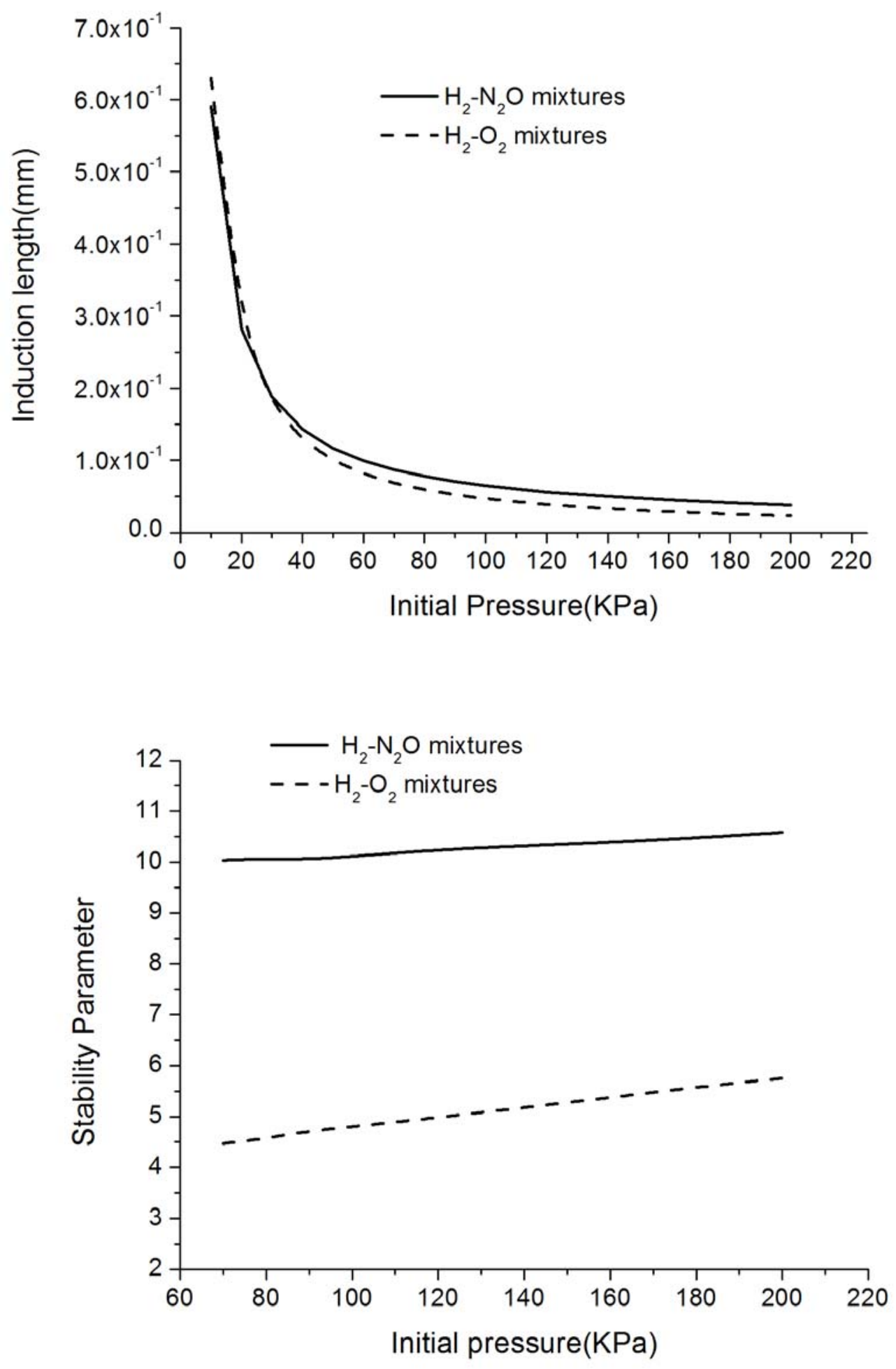

Fig. 12. 


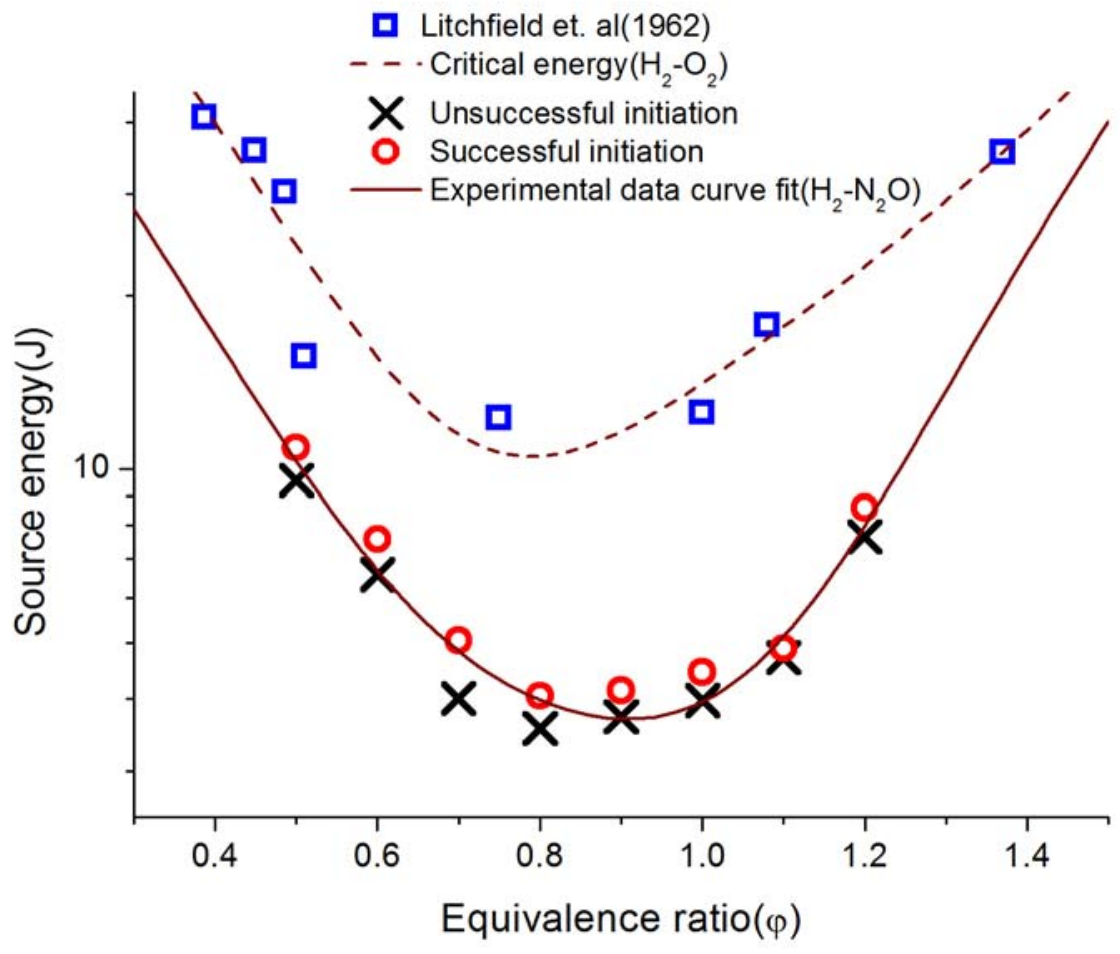

Fig. 13. 

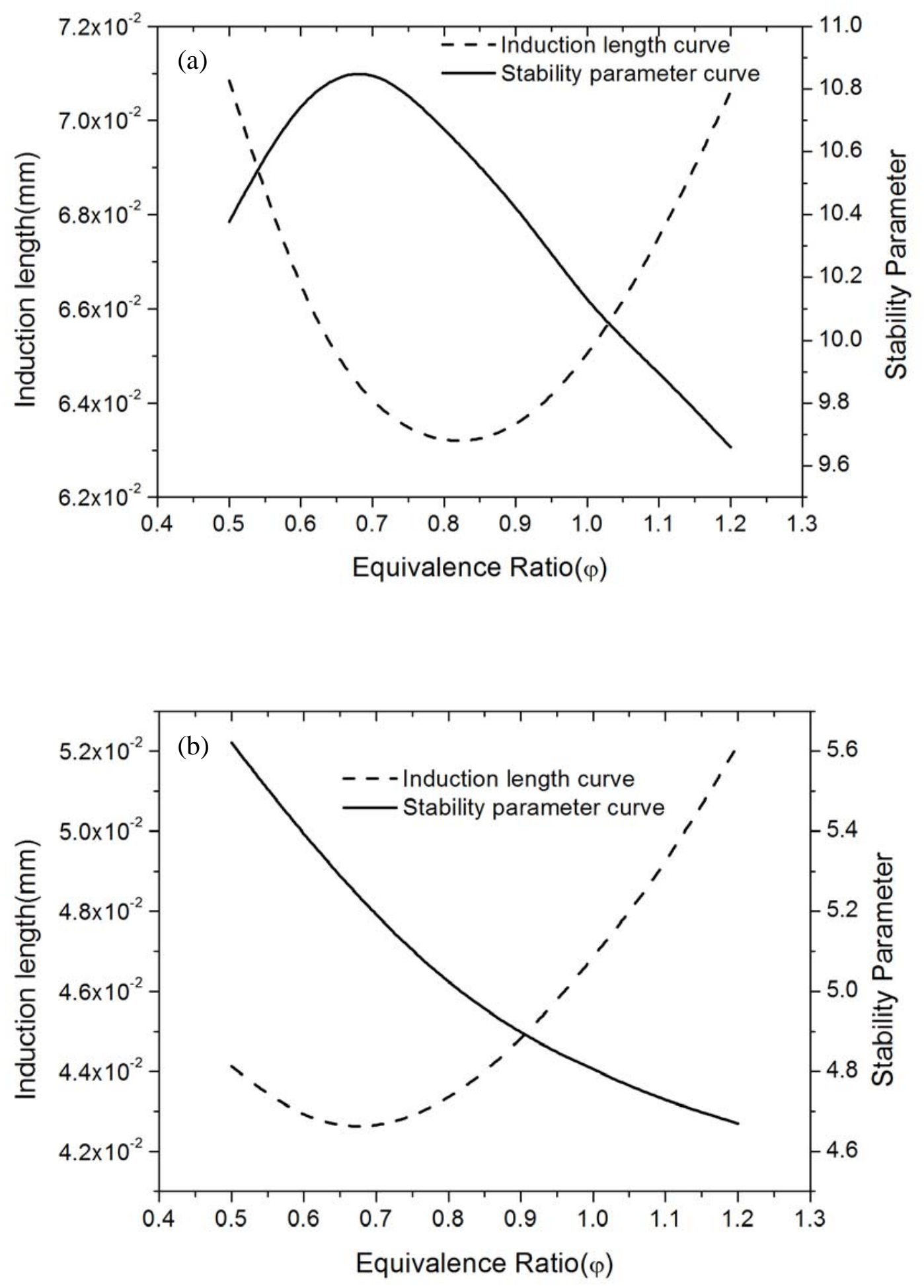

Fig. 14. 


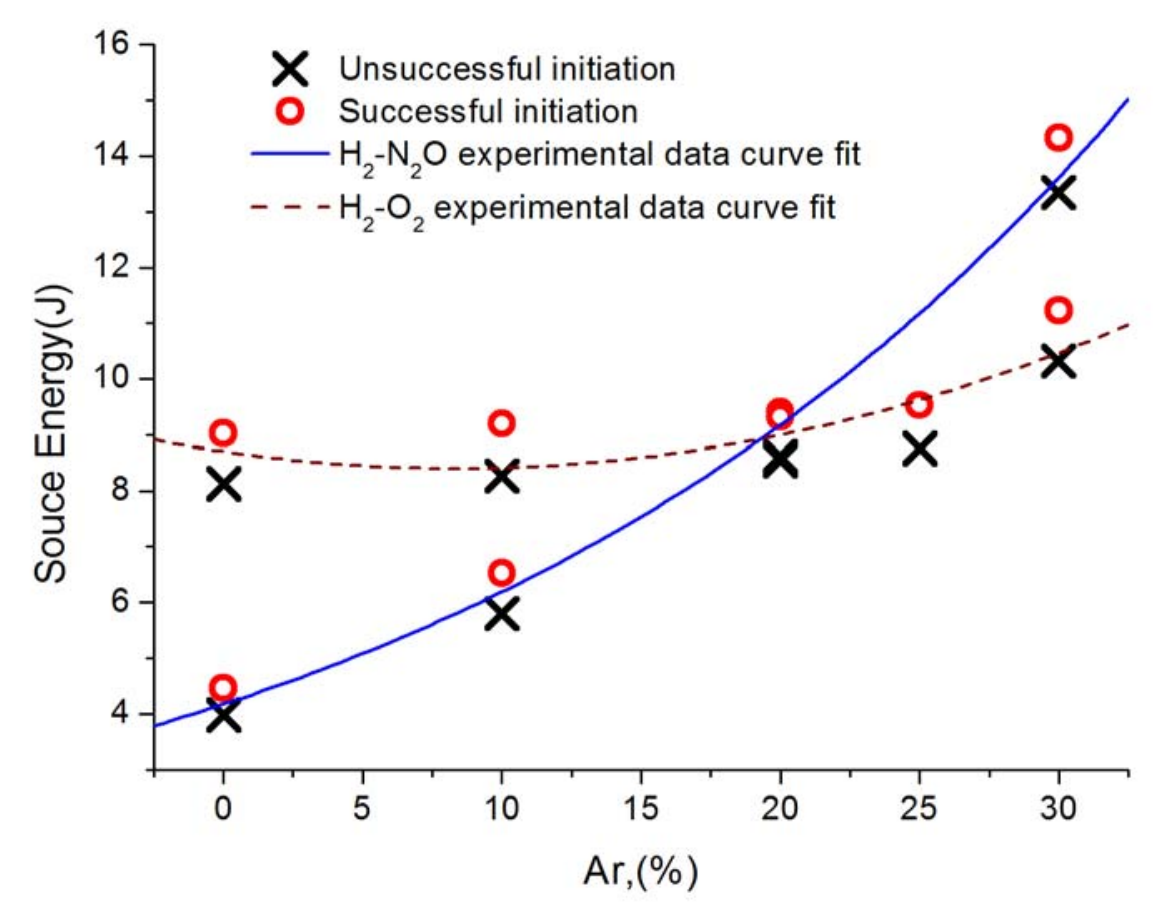

Fig. 15. 


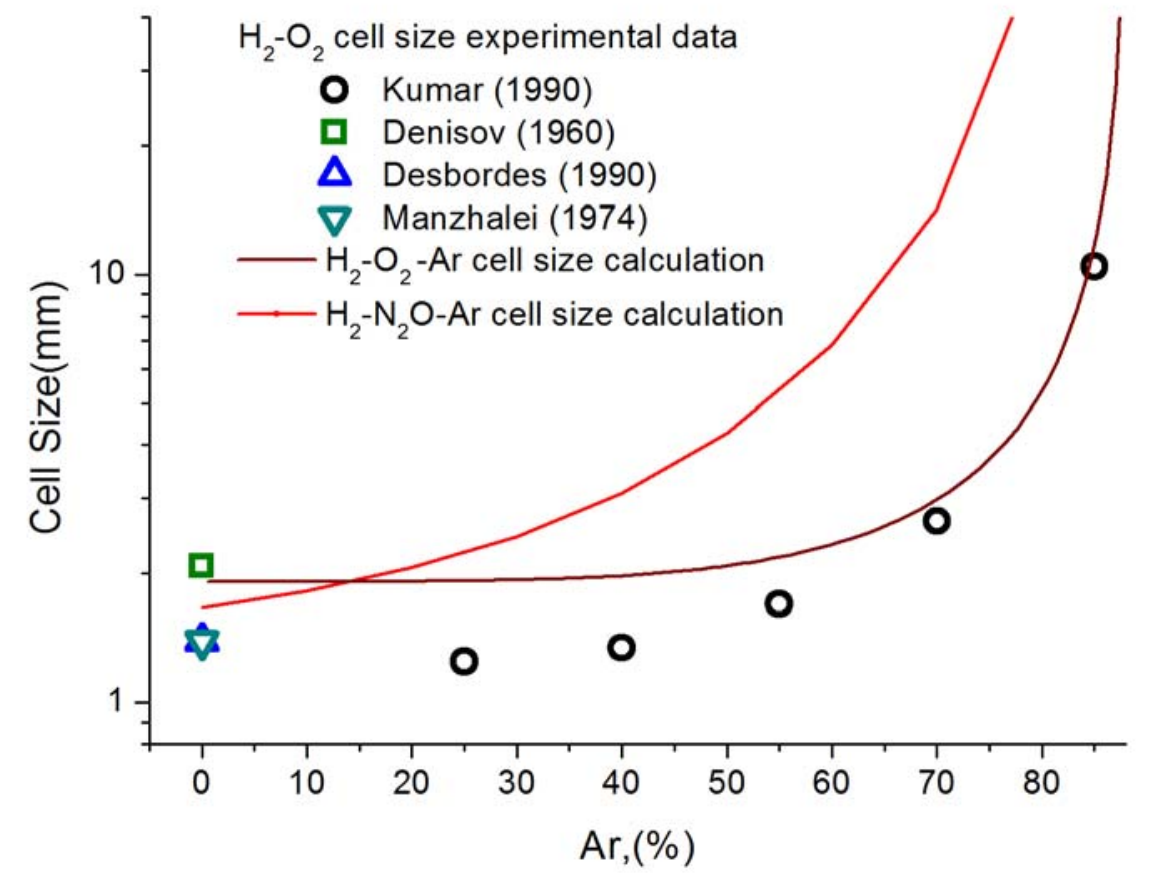

Fig. 16. 

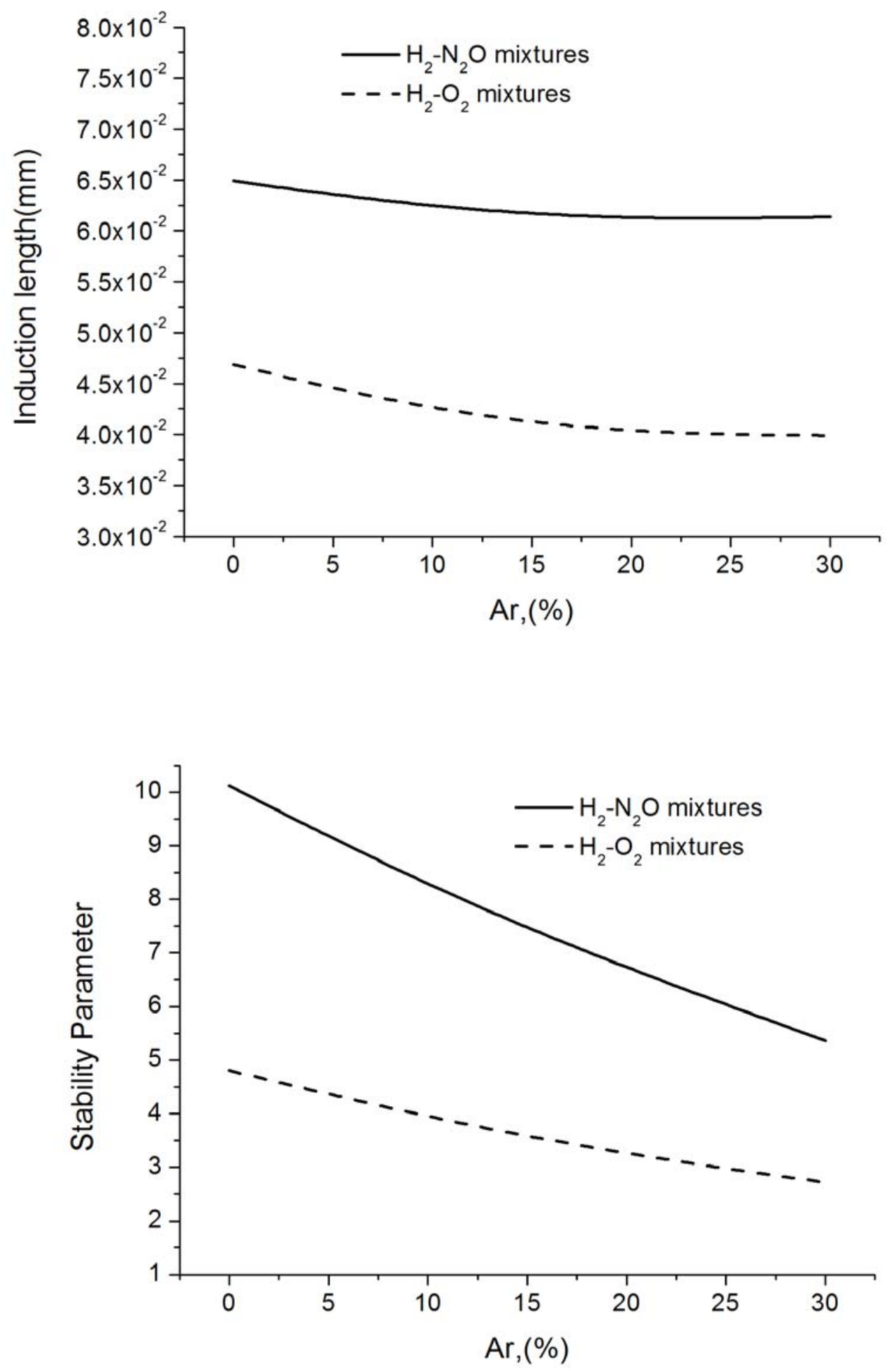

Fig. 17. 